\title{
A COMPUTER-CONTROLLED AUTOMATED TEST SYSTEM FOR FATIGUE AND FRACTURE TESTING*
}

R. K. Nanstad, D. J. Alexander, R. L. Swain, J. T. Hutton, ${ }^{+}$and D. L. Thomas ${ }^{+}$

Metals and Ceramics Division Oak Ridge National Laboratory P.0. Box 2008

Oak Ridge, Tennessee 37831-6151

CONF-8905112--3

DE90 002931

\section{ABSTRACT}

A computer-controlled system consisting of a servohydraulic test machine, an in-house designed test controller, and a desktop computer has been developed for performing automated fracture toughness and fatigue crack growth testing both in the laboratory and in hot cells for remote testing of irradiated specimens. Both unloading compliance and dc-potential drop can be used to monitor crack growth. The test controller includes a dc-current supply programer, a function generator for driving the servohydraulic test machine to required test outputs, five measurement channels (each consisting of low-pass filter, track/hold amplifier, and 16-bit analog-to-digital converter), and digital logic for various control and data multiplexing functions. The test controller connects to the computer via a 16 -bit wide photo-isolated bidirectional bus. The computer, a Hewlett-Packard series 200/300, inputs specimen and test parameters from the operator, configures the test controller, stores test data from the test controller in memory, does preliminary analysis during the test, and records

"Research sponsored by the office of Nuclear Regulatory Research, U.S. Nuclear Regulatory Commission, under Interagency Agreement DOE 1886-8011-9B with the U.S. Department of Energy under contract DE-AC05-840R21400 with Martin Marietta Energy Systems, Inc.

${ }^{+}$Instrumentation and Controls Division.

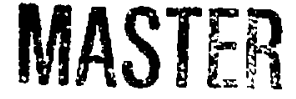

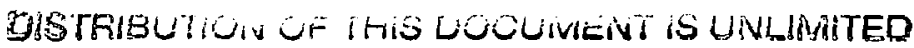

The submitted manuscript has been outhored by - contrector of the U.S. Government unde contrect No. DE-ACO5-84OA2 1400. Accordinghy the U.S. Government retein - nonexchesive. royaltr-fies lanes to publiah or reproduce the published form of this contribution, of bllow othere to do so. for U.S. Gowerrment purposea.- 


\section{DISCLAIMER}

This report was prepared as an account of work sponsored by an agency of the United States Government. Neither the United States Government nor any agency thereof, nor any of their employees, makes any warranty, express or implied, or assumes any legal liability or responsibility for the accuracy, completeness. or usefulness of any information, apparatus, product, or process disclosed, or represents that its use would not infringe privately owned rights. Reference herein to any specific commercial product, process, or service by trade name, trademark, manufacturer, or otherwise does not necessarily constitute or imply its endorsement, recommendation, or favoring by the United States Government or any agency thereof. The views and opinions of authors expressed herein do not necessarily state or reflect those of the United States Government or any agency thereof. 
sensor calibrations.specimen and test parameters, and test data on flexible diskette for later recall and analysis with measured inttial and final crack length information. During the test, the operator can change test parameters as necessary.

\section{KEY WORDS}

Computer, fatigue, crack growth, fracture toughness, test controller, compliance, dc-potential, J-integral, multichannel, J-R curve, analog-to-digital, photo-isolation, CMOS, clip gage, automation, interface.

\section{INTRODUCTION}

The automation of materials testing equipment is certainly not a recent concept. Researchers have applied various degrees of automation over the years with the general objectives of increasing productivity, efficiency, and consistency. The advent of desktop laboratory computer systems capable of machine control and data acquisition was the real catalyst in this area, and the result has been an explosion of computer automation. This is evident from the relatively narrow technical field for which this symposium was developed. The applications for computer automation span the entire range of technology. The characteristics of automated systems are as diverse as the applications, reflecting the particular needs of the user. Some are hard, dedicated, inflexible systems which perform precisely the same set of tasks for every opexation, while others have a high degree of flexibility and adaptability. The needs of the fracture and fatigue testing community span that range. The rapid 
evolution of sophisticated desktop computers, peripheral devices, and other electronic hardware, in terms of speed and memory capacity, has likewise allowed for increasingly greater flexibility and capability in the software for test control, data acquisition, storage, and analysis.

The Fracture Mechanics Group of the Metals and Ceramics Division at Oak Ridge National Laboratory began a computer automation activity in 1978 for the purpose of conducting elastic-plastic fracture mechanics tests. The system has evolved markedly since then, particularly in terms of speed. The need for test control and rapid data acquisition during fatigue crack growth testing spurred the development of a high-speed, multichannel test controller. This paper describes the computer-automated system, test and analysis procedures, and some test results.

\section{BACKGROUND}

Automated testing for evaluation of fracture resistance was largely spurred by developments in elastic-plastic fracture mechanics. Starting with the concept of the $\mathrm{J}$-integral by $\mathrm{Rice}^{1}$ and the description of a practical means for estimating $\mathrm{J}$ vs crack extension in test specimens by Rice et al. ${ }^{2}$ the advantages of computer involvement were apparent. It was the development of the unloading compliance test method, ${ }^{3}$ however, which forced the incorporation of computers in tes: systems. The unloading compliance test procedure requires excellent test control, high-precision data acquisition capability, and rapid calculation. The use of computers for automated unloading compliance testing has been described by a number of researchers. $4,5,6$ 
Although the unloading compliance technique is an accepted procedure for determining $J_{I c}$ and $J$ resistance $(J-R)$ curves in ASTM standards, obtaining accurate and consistent test results is not an easy task. Because the unloading compliance technique involves a fairly large number of periodic unloading cycles, usually with a hold period at the start of each cycle to allow for load relaxation in the system, the testing time can be on the order of one hour. In many instances, especially those involving remote testing of irradiated specimens in a hot cell, the high expense of facilities and equipment mandate that all feasible reductions in testing time be effected. Because the unloading compliance test requires high-precision measurements of displacement during each unloading cycle, the extensometer (usually a clip-on displacement gage) is very important. The extensometer must be carefully calibrated and must be seated in such a way that effects of error sources such as friction and vibration are minimized. Testing at low and high temperatures adds temperature shifts in extensometer calibration as another source of error. The ability to accurately infer crack length without resorting to unloading the specimen (with the associated extensometer and sources of error) has made the dc-potential drop (dcpd) method for determining the crack length a widely used technique for both fracture mechanics $(\mathrm{J}-\mathrm{R})^{4}$ and fatigue crack growth $(F C G)^{7}$ tests. Dc-pd is an importanc aspect of the testing system and analysis procedures described herein.

\section{DESCRIPTION OF TEST SYSTEM}

Figure 1 shows a block diagram of the major components of the interactive fracture mechanics test system. The computer is a Hewlett-Packard series $200 / 300$ with 4 MB of random-access memory and Hewlett-Packard technical BASIC operating 
system and runs a $1.024-\mathrm{MB}$ test control/data acquisition and analysis program developed in-house specifically for this application. The computer connects to the test controller via a 16-bit wide photo-isolated bidirectional control/data bus. The test controller (prototype shown in Fig. 2) j.ncludes a dc-current programmer for controlling a Kepco model ATE6-100M power supply operated in current-regulation mode, a ramp and sine output function generator for programming an MTS or Instron servohydraulic test machine, five measurement channels (each consisting of 8-pole low-pass filter, track/hold amplifier, and 16-bit successive-approximation analog-to-digital converter) for reading the test machine signal conditioner and low-roise dc-pd amplifier outputs, and complementary metal oxide semiconductor (CMOS) digital logic.

The dc-current programmer consists of a 12-bit digital-to-analog converter and a transformer-isolated output amplifier and can set the output of the dc-current supply over a range of 0 to $100 \mathrm{~A}$.

Function generator ramp outputs (used in J-R testing) are obtained by using a 12-bit digital-to-analog converter to set input current to an operational amplifier integrator; this results in ramp outputs that are smooth and stepless even at low ramp rates. The range of ramp rates available is split into three subranges $(0.00005$ to $0.1 \mathrm{dc} \mathrm{V} / \mathrm{s}, 0.1$ to $10 \mathrm{~cd} \mathrm{~V} / \mathrm{s}$, and 10 to $1000 \mathrm{dc} \mathrm{V} / \mathrm{s}) \mathrm{by}$ switching to different subrange capacitors in the integrator; this results in reasonable resolution in selection of nominal ramp rate. When the computer orders the ramp output to hold, the digital-to-analog converter current is disconnected from the integrator, and the integrator output voltage remains constant. An auxiliary 12-bit digital-to-analog converter is used to null integrator input offset currents which would cause integrator output voltage drift during holds. The test controller has memory locations for up to eight 
ramp segments (consisting of ramp rate and endpoint voltage) which can be loaded from the computer to generate arbitrary waveforms (such as triangle, trapezoidal, etc.) Function generator sine outputs (used in FCG testing) are obtained by feeding a triangle waveform (the sine argument) from the integrator to an integrated circuit sine wave generator. Amplitude and mean value of the sine wave are programmed by 12-bit digital-to-analog converters.

The test controller reads the servohydraulic test machine load and extension conditioner output voltages by means of 16 -bit analog-to-digital converters fed through 8-pole low-pass filters with computer-programmed frequency break points (usually $10 \mathrm{~Hz}$ for a $\mathrm{J}-\mathrm{R}$ test and $200 \mathrm{~Hz}$ for a $20-\mathrm{Hz}$ FCG test) and precision track/hold amplifiers. The track/hold amplifiers snapshot the respective filter outputs at the start of each analog-to-digital conversion cycle so that the signals are not changing during analog-to-digital conversion. Active and reference dc-pd voltages are amplified by in-house developed low-noise instrumentation amplifiers and then read with the same type of low-pass filter, track/hold amplifier and analog-to-digital converter circuitry used for load and extension channels. The analog-to-digital converters are all triggered simultaneously (which eliminates time skew between channels), and the readings are saved in latches (which allows the next analog-to-digital conversion cycle to start immediately in high-frequency FCG testing) and then multiplexed back to the computer. The sequence of channel readings multiplexed back to the computer each analog-to-digital converter cycle (the data frame) are loaded to the test controller by the computer before the test starts. During the test the required channels (load and extension for $J-R$ testing and load, extension, active dc-pd voltage, and reference dc-pd voltage for FCG testing) are automatically sent back to the computer in the data frame at rates up to 2500 frames/s. 
The test controller contains a cycle counter (advanced by the sine output of the function generator) and cycle counts can be included in the data frame. Trigger modes built into the test controller include demand (low speed, used in $\mathrm{J}-\mathrm{R}$ tests), pacer (high speed, used in FCG tests) and waveform maximum/minimum. The test controller is designed to be calibrated and adjusted entirely by the computer and an external digital voltmeter; no zero or range potentiometers for the various digital-to-analog and analog-to-digital converters are included or needed. CMOS digital logic was chosen for low power consumption and adequate speed ( $1-\mathrm{MHz}$ clock rate).

Acceptable operation of the test system in test control and data acquisition depends upon the minimization of noise pickup, primarily $60 \mathrm{~Hz}$. A number of features provide electrical isolation of system components so that a singlepoint grounding system can be implemented. The test controller incorporates photo-isolation on all input/output lines to the computer and programming lines to the dc-current supply, the extensometer is electrically isolated from the specimen by using Teflon spacers between the razor blades and the specimen, and the specimen grips are electrically isolated from the load frame by ceramic inserts in the load train ball joints. The single-point ground chosen is that of the servohydraulic test machine electronics. Heavy-gage grounding cables connect the test controller data acquisition common, the dc-current supply output, and the low-noise dc-pd amplifier common to the single-point ground. Since all system components are initially isolated, no ground loops (with the inherent $60-\mathrm{Hz}$ noise pickup) are formed by the single-point grounding procedure. Electrical isolation of the specimen grips also prevents shunting of dc-current around the specimen. The grounding scheme has proved to be effective in minimizing noise pickup. 
DESGRIPTION OF EXTENDED RANGF CITP-ON DTSPIACEKENT GAGE

For many tests a commercially produced clip-on displacement gage meets all requirements for an extensometer, but testing at extreme temperatures or over extended displacement ranges necessitates the use of an in-house developed clipon displacement gage. The in-house gage has an operating temperature range of -196 to $300^{\circ} \mathrm{C}$, and calibration (at $25^{\circ} \mathrm{C}$ ) over a 1.27 to $20.3 \mathrm{~mm}(0.050-0.800 \mathrm{in}$.) displacement range shows a very linear behavior. Because the clip-on displacement gage is used over a wide temperature range and because the unloading compliance test technique requires high precision, an experiment was undertaken to examine calibration shifts as a function of temperature. Calibrations were performed at $-196,-73,25,100,200$, and $288^{\circ} \mathrm{C}$ over a 3.78 to $16.5 \mathrm{~mm}$ (0.150-0.650-in.) displacement range. Third degree polynomial fits were calculated for the voltage vs displacement data at the different temperatures. Al1 residuals between the data and fits were $2.5 \times 10^{-4} \mathrm{~mm}\left(10^{-5}\right.$ in. $)$ or less. Comparison of the fits revealed that first order coefficients for low and high temperatures varied less than 48 from that at room temperature. A second calibration at $25^{\circ} \mathrm{C}$ following the high and low temperature calibrations agreed with the original calibration within about 18 . Because the temperature effects were found to be relatively insignificant most testing and analysis is done with calibrations performed at room temperature, not at test temperature. It should be noted that the term "calibration" as used above refers to a process of relating binary data values to corresponding engineering unit results using a higher-order polynomial function, not to a determination of strain errors based on a linear function (as in ASTM E 83). 


\section{DC-POTENTIAL DROP CALIBRATION}

For accurate determination of crack length with the dc-pd technique, an accurate calibration relating dc-pd voltages and crack length is essential. Johnson $^{8}$ developed a relatively general relationship used by many researchers, and other calibrations are presented in the literature for various fracture mechanics specimens, ${ }^{9,10}$ including an experimental and numerical analysis ${ }^{4}$ of the compact specimen. For this program, however, a stuly was undertaken to examine the effects of potential drop and current input lead locations on the calibration using both experimental and numerical methods. This paper summarizes that study; a comprehensive discussion will be published separately.

Aluminum sheet specimens $3.17 \mathrm{~mm}$ thick (0.125 in.) were fabricated with overall planar dimensions eight-times those of the standard $1 / 2 T$ compact (C(T)) specimen in ASTM E 813. The dc-pd voltages across the specimen slot, using various combinations of current input lead and dc-pd voltage (both active and reference) lead locations, were measured for a series of specimens having very narrow slots of lengths (ratio of crack length to width, a/w) from 0.25 to 0.95 . The probes for each specimen were spot-welded in place. Figure 3 shows the finite-element mesh and one combination of dc-pd lead locations investigated for the $1 / 2 \mathrm{~T} \mathrm{C}(\mathrm{T})$ specimen configuration. The ADINAT finite-element code was used to numerically determine calibrations for the same combinations of variables. A comparison of the experimental and numerical calibrations is shown in Fig. 4. The results are in excellent agreement and validate the use of the numerical aralysis techniques co provide reliable calibrations for different geometries and probe locations. All of the results are based on ratios of pd-active and pd-reference voltages. This approach cancels out the effects of slow changes 
in dc-current, changes in specinen electric resistance caused by slow changes in test temperature, different specimen materials, and different specimen sizes; one fourth-order poiynomial fit to the aluminum sheet specimen data shown is used for all $\mathrm{J}-\mathrm{R}$ and FCG testing.

\section{ELASTIC-PLASTIC FRAGTURE MECHANICS TESTING}

Fracture mechanics tests are performed to evaluate plane-strain fracture toughness, $K_{I c}$, ductile fracture initiation toughness, $J_{I c}, J-R$ curve behavior, and an elastic-plastic determination of toughness at the onset of cleavage, $\mathrm{K}_{\mathrm{Jc}}$. The $K_{J c}$ is determined by calculating the $J$-integral at the onset of cleavage, $J_{c}$, then using the equation, $\mathrm{K}_{\mathrm{Jc}}-f\left(\mathrm{EJ}_{\mathrm{c}}\right)$, where $\mathrm{E}$ is Young's modulus. The test specimen is usually the $C(T)$ geometry, although modiflcations to the software can be implemented .o allow for virtually any specimen geometry providing the operative analytical equations are known. The system has been used with $89 \mathrm{kN}$ MTS, $445 \mathrm{kN}$ MTS, and $890 \mathrm{kN}$ Instron (20, 100, and $200 \mathrm{kip}$, respectively) aulic test machines.

\section{TEST PROCEDURES}

Before the test starts the computer prompts the operator for information regarding servohydraulic test machine in use, specimen dimensional and material information, test temperature, crack length determination method (unloading compliance and/or dc-pd), and displacement rates for lrading and unloading. $J-R$ tests are usually conducted in strain control with feedback to the servohydraulic test machine derived from a clip-on displacement gage seated on 
razor blades usually positioned at the specimen load line, although other locations can be accommodated. A series of computer prompts specifies inftial settings for all servohydraulic test machines switches and controls and the correct sequence for mounting the specimen in the grips, turning on hydraulic pressure, etc.

After the specimen is equilibrated at test temperature, but prior to the actual testing, the specimen is cycled between high and low loads (both loads are chosen to be less than the maximum load used in precracking the specimen) twice to seat the clip-on displacement gage on the razor blades. The program displays a plot of specimen load vs displacement and prompts the operator regarding satisfactory gage seating. The next step involves the acquisition and averaging of $60 \mathrm{dc}$-pd readings (taken over about a 1.5 -s interval) to determine the initial values of pd-voltages which will be used to calculate the dc-pd value for initial crack length. The specimen is similarly cycled a third time to obtain the initial value of compliance which, together with the previously entered estimate for initial crack length, is used to calculate an effective modulus (as specified in ASTM E 813). Additionally, a correction factor which forces the extrapolated load-displacement trace through the origin is calculated and applied to all subsequent displacement data.

If the operator accepts the value for compliance, the test starts. The Initial slope of the load-displacement trace is used to determine the 958 secant offset line as described in ASTM E 399. As the load increases, the computer continually calculates the corresponding secant offset line displacement. When three successive specimen displacements exceed that of the secant line, assuming the specimen had not failed during loading, the load at which the trace crossed the secant line is designated $P_{Q}$. Loading is continued until a load 
corresponding to $1.1 \times \mathrm{P}_{\mathrm{Q}}$ is reached, and a hold period, generally 10 to $20 \mathrm{~s}$ long, is infiated to allow for load relaxation in the system. The target load of $1.1 \times P_{Q}$ was selected based on the provision in ASTM E 399 that a maximum load which exceeds that value negates the determination of a valid $K_{I c}$. The intent is to preserve the purity of a test which experiences brittle fracture under conditions which might result in a valid $\mathrm{K}_{\mathrm{Ic}}$. During the hold period, the computer acquires and stores 60 readings of bcth pd-active and pd-reference voltages with full current and zero current. The zero-current readings are used to subtract out electronic drift and thermal emf effects. At the completion of the hold period, the specimen is unloaded, then reloaded and another hold period started. The amount of unloading is dependent on the accuracy of the compliance determined during the previous unloading (a statistical analysis of the unloading data is performed). If the current-cycle compliance accuracy is unsatisfactory, the unload-reload sequence will be repeated with a greater amount of unloading. The maximum unloading allowed is $50 \%$ of the load at the end of the first hold period and is generally about 158 .

During the second hold, the pd-active and pd-reference voltages with full and zero current are used to calculate the dc-pd value for crack length and the compliance and effective modulus are used to calculate the unloading compliance value for crack length. These results, the load, extension, area under the loaddisplacement curve, and J-integral at the end of the cycle are all output to the printer, and a plot of $\mathrm{J}$ vs crack extensions is displayed on the CRT before continuing the test.

The displacement increment for the next test cycle is calculated as a percentage (specified by the operator as one of the test parameters) of the displacement at the first unloading point $\left(1.1 \times P_{Q}\right)$. Use of that increment 
continues until the $\mathrm{J}$ vs crack extension curve crosses the second exclusion line as defined in ASTM E 813. After that, each succeeding displacement increment is calculated as a percentage of the previous displacement so that the displacements become progressively greater as the test continues. The load-line displacements are also corrected for changes in specimen geometry with large openings. ${ }^{11}$ The test is stopped automatically when the specimen fractures or the target end displacement is reached, or when the operator intervenes. Then the computer does final calculations for estimated crack length, crack extension, load, displacement, area under the load vs crack extension curve, and J-integral. If the specimen did not fracture, the crack front is marked. For steels the specimen is heat-tinted at about $300^{\circ} \mathrm{C}$ until the surfaces are obviously discolored, and then broken open after being cooled in liquid nitrogen. For other materials, such as aluminum, the crack front is marked by fatigue cycling for several thousand cycles and then broken open.

\section{ANALYSIS PROCEDURES}

The length of the fatigue precrack and the final crack length are measured, as prescribed in ASTM E 813, using a digital measuring microscope. The computer analysis routine uses the measured initial crack length value and the compliance determined at the initial test unloading to calculate an effective modulus (the equation in ASTM E 813 is used) which is used for the balance of the analysis. If dc-pd data is to be analyzed, a plot of pd-voltage ratio vs displacement is displayed on the CRT and the operator prompted to determine the point at which crack opening effects were complete (usually the start of an initial linear relation between the pd-voltage ratio and the displacement), and the dc-pd 
polynomial function is normalized to give the measured initial crack length for the pd-voltage ratio at that point. This procedure differs from that described by Lowes and Fearnehough, ${ }^{12}$ and used by others, ${ }^{13-15}$ and investigations to determine which of the procedures gives the more reliable results are continuing. Any combination of three different $\mathrm{J}$-integral formulations may be calculated: (1) the deformation J given in ASTM E 1152, (2) the so-called modified $J$ of Ernst ${ }^{16}$ (formulated to account for crack extension), and (3) the Merkle-Corten $\mathrm{J}^{17}$ (formulated to account for the tensile component in compact specimens). The selected $J$ values, crack length information, etc., are printed in SI and/or English units for each test cycle. Portions of the load vs displacement curve showing $P_{Q}$ and maximum load can be displayed on the CRT and dumped to the printer if the operator chooses. A value of $k_{Q}$ is calculated according to ASTM E 399, and J values are calculated at maximum Inad and the point of unstable fracture $\left(J_{c}\right)$. The value of $k_{Q}$ is evaluated for ASTM E 399 validity and, if appropriate, designated a valid $K_{I c}$. Final measured crack length is compared to those predicted by unloading compliance and dc-pd analyses, and the differences in crack extension printed. The $B_{I c}$ adjustment described by Merkle, ${ }^{18}$ to account for loss of constraint in the transition region of ferritic steels, is used to adjust the $K_{J c}$ value to a $K_{B C}$.

The operator can invoke a power-law regression routine which fits the selected $J$ vs crack extension results. The routine displays the results and the power-law fit on the CRT and prompts the operator to accept the fit; if the fit is rejected, any suspect test results may be excluded and the regression 
repeated. Once the fit is accepted, the power-law fit plot (including ghosted symbols for any excluded results) is dumped to the printer, $J_{I_{c}}$ is determined in accordance with ASTM E 813, and the tearing modulus ${ }^{19}$ is calculated.

The agreement between final measured and predicted crack extensions is generally within 58 and rarely exceeds the $15 \%$ criterion in ASTM E 813. This is true for both unloading compliance and dc-pd analyses. Figure 5 shows a representative example of a $J-R$ test result obtained with this system and test procedure. At the $538^{\circ} \mathrm{C}\left(1000^{\circ} \mathrm{F}\right)$ test temperature, pin rotation problems caused very poor crack length prediction by the unloading compliance technique, but the dc-pd predictions were excellent. Future research in this area will involve the use of dc-pd techniques to infer crack extension in a high-rate J-R test. Some of the known problems associated with high-rate loading are discussed in the following section on fatigue crack growth rate testing.

\section{FATIGUE CRACK GROWTH TESTING}

A primary motivation for the development of the test controller was the desire to obtain precision measurements of load, displacement, and dc-pd voltages at high rates during FCG testing. Many examples of computer-controlled fatigue crack growth rate testing are available in the literature, ${ }^{20.21}$ and the methods for acquiring and analyzing the data are varied. Likewise, the methods for determining crack length are varied, not only in terms of the measurement technique (unloading compliance and dc-pd), but also in terms of data and waveform analysis. In the case of dc-pd, for example, some experimenters read the peaks of the voltage waveform during cycling, while others choose to collect 
data over a specific region on the waveform. All the techniques are chosen with the goal of obtaining the most representative dc-pd voltages for the crack length at the time of the reading.

One of the primary problems associated with this type of cyclic testing is the occurrence of large fluctuations in the dc-pd signals. These fluctuations have been identified by various investigators 22,23 to be due to inverse magnetostriction effects, the so-called villari effect. This effect exists when strain applied to ferromagnetic material induces anisotropy of magnetic properties. Davis and Plumbridge ${ }^{24}$ conducted an extensive investigation of these effects. They reported that the fluctuations are proportional to strain rate and that crack closure effects are minor by comparison.

During experiments for this program using a $1 T C(T)$ specimen instrumented as described for $\mathrm{J}-\mathrm{R}$ testing and a multi-channel digital oscilloscope, similar large fluctuations were recorded at load cycle frequencies ranging from 0.1 to $30 \mathrm{HZ}$. The oscilloscope traces were taken with full current and zero current, with and without cyclic loading. Figure 6 shows one example of the waveforms obtained from such an experiment. The use of high-capacitance electrical filters to eliminate the fluctuations was rejected because of the waveform distortion and interchannel phase shift problems caused by that approach; instead, various data manipulation strategies were investigated. The result of these studies was the development of a technique using pd-voltage sampling over complete load cycles with full and zero dc-current. The full and zero current technique (which avoids the need for bipolar dc-current supplies or current-reversing switch contacts in the current path) cancels errors due to thermal emf and slow dcelectrical drift in the pd-voltage amplifiers. Integration of the pd-voltage 
readings from a load cycle gave mean values for pd-active and pd-reference voltages that were within 0.58 of the voltages read in the static load case.

After incorporating the sampling and analysis techniques in computer software that could exercise the test controller, the test system described for $J-R$ testing was used to perform similar experiments and to verify that the test controller is capable of conducting tests at load cycle frequencies up to $30 \mathrm{~Hz}$. For each pd-voltage sampling, the load, pd-active and pd-reference voltage waveforms are read twice, once with full current and once with zero current. About 100 readings are taken for each waveform to be sure that at least one load cycle will be covered from start to end. The zero current readings are subtracted from the corresponding full current readings (correspondence is determined by reference to the load waveform), and the results averaged to obtain one reading fer each voltage. For a test conducted at $20 \mathrm{~Hz}$, the test variables are sampled (read with full current, dc-current supply programmed for zero current, read again, and dc-current supply programmed for full current) and manipulated within about $1.5 \mathrm{~s}$. The software contains logic to determine if a data point is significant based on the change from the last crack extension value. If a point is determined to be significant, the load, pd-active and pdreference voltage waveform data for that cycle are saved along with cycle number and the crack extension data point. The testing performed so far has yielded very promising results. Software for the test system and analytical techniques described is being developed for various types of FCG tests (constant load, constant $K$, decreasing $K$, constant $K_{\max }$-increasing $R$ ratio, etc.), and specific test results will be reported separately. 


\section{SUMMARY}

A computer-controlled system has been developed for J-R and FCG testing. The test system is comprised of a laboratory desktop computer running calibration/test/analysis software, test controller, dc-current supply, and servohydraulic test machine. Development of the computer software and the test controller in-house ensures an open system that can be adapted to mett changing $\mathrm{J}-\mathrm{R}$ and FCG test requirements. A modular approach in software development insures that operator interaction, error checking and recovery, and test controller utility subprograms can be readily applied to other testing such as tensile, crack-arrest, fatigue, etc. The test controller provides high-speed, high-precision test control and data acquisition. Both unloading compliance and dc-pd techniques can be used to monitor crack extension for $J-R$ tests. Dc-pd is used for uninterrupted FCG testing at load cycle rates up to $30 \mathrm{~Hz}$. Test errors, such as those due to inverse magnetostriction effects (Villari effect) and thermal emf effects, are eliminated by a full current/zero current, full waveform sampling and averaging technique. 


\section{ACKNOWLEDGKENTS}

The authors acknowledge the valuable contributions of John J. McGowan, formerly of ORNL, to the initial phase of work on the test controller. We extend our appreciation to R. W. Swindeman and S. K. Iskander for manuscript technical review and Julia L. Bishop for manuscript preparation. We appreciate the support from the Heavy-Section Steel Technology Program at ORNL, managed by William R. Corwin, and sponsored by the U.S. Nuclear Regulatory Commission, Michael E. Mayfield, HSST Program Technical Monitor. 


\section{REFERENCES}

1. Rice, J. R., "A Path Independent Integral and the Approximate Analysis of Strain Concentrations by Notches and Cracks," J. Appl. Mechanics, Transactions, American Society of Mechanical Engineers, 35, 379-86 (1968).

2. Rice, J. R., Paris, P. C., and Merkle, J. G., "Some Further Results of J-Integral Arialysis and Estimates," pp. 231-45 in Progress in Flaw Growth and Fracture Toughness Testing, STP 536, J. G. Kaufman, Ed., American Society for Testing and Materials, Philadelphia, 1973.

3. Clarke, G. A., Andrews, W. A., Paris, P. C., and Schmitt, D. W., "Single Specimen Tests for $J_{I c}$ Determination," pp. 27-42 in Mechanics of Crack Growth, STP 590, J. R. Rice and P. C. Paris, Eds., American Society for Testing and Materials, Philadelphia, 1976.

4. McGowan, J. J., and Nanstad, R. K., "A Direct Comparison on Unloading Compliance and Potential Drop Techniques in J-Integral Testing," pp. 136-40 in Proceedings of the 1984 SEM Fall Conference, Computer-Aided Testing and Modal Analysis, Milwaukee, Nov. 4-7, 1984, Society for Experimental Mechanics, Brookfield Center, Conn., 1984.

5. Clarke, G. A., and Brown, G. M., "Computerized Methods for J Ic Determination Using Unloading Compliance Techniques," pp. 110-26 in Computer Automation of Materials Testing, STP 710, B. C. Wonsiewicz, Ed., American Society for Testing and Materials, Philadelphia, 1980.

6. Joyce, J.A., and Gudas, J. P., "Computer-Interactive $J_{\text {Ic }}$ Testing of Navy Alloys," pp. 451-68 in Elastic-Plastic Fracture, STP 668, J. D. Landes, J. A. Begley, and G. A. Clarke, Eds., American Society for Testing and Materials, Philadelphia, 1979. 
7. Halliday, M. D., ano Beevers, C. J., "The de Electrical Potential Method for Crack Length Measiurement," pp. 85-112 in The Measurement of Crack Length and Shape During Fracture and Fatigue, C. J. Beevers, Ed., Engineering Materials Advisory Services, Ltd., London, 1980.

8. Johnson, H. H., "Calibrating the Electric Potential Method for Studying Slow Crack Growth," Mater. Res. Stand. 4, 442-45 (1965).

9. Ritchie, R. O., and Bathe, K. J., "On the Calibration of the Electrical Potential Technique for Monitoring Crack Growth Using Finite Element Methods," Int. J. Fracture 15(1), 47-55 (1979).

10. Freeman, B. L., and Neate, G. J., "The Measurement of Crack Growth During Fracture at Elevated Temperatures Using the dc-Potential Drop Technique," pp. 435-59 in The Measurement of Crack Length and Shape During Fracture and Fatigue, Engineering Materials Advisory Services, Ltd., Warley, England, 1980.

11. Gray, R. A., Jr., Loss, F. J., and Merke, B. H., "Development of J-R Curve Procedures," NRL-EPRI Research Program (RP 886.2), Evaluation and Prediction of Neutron Embrittlement in Reactor Pressure Vessel Materials, Annual Progress Report for CY 1978, NRL Report 8327, Naval Research Laboratory, Washington, D.C., August 1979.

12. Lowes, J.M., and Fearnehough, G. D., "The Detection of Slow Crack Growth in Crack Opening Displacements Using the Electrical Potential Method," Engineering Fracture Mechanics, 3, 103-108 (1971).

13. Vassilaros, M. G., and Hackett, E. M., "J-Integral R-Curve Testing of High Strength Steels Utilizing the Direct Current Potential Drop Method," pp. 535-552 in Fracture Mechanics, Fifteenth Symposium, STP 833, R. J. Sanford, Ed., American Society for Testing and Materials, Philadelphia, 1984. 
14. Hackett, E. M., Kirk, M. T., and Hays, R. A., An Evaluation of $J-R$ Curve Testing of Nuclear Piping Materials Using the Direct Current Potential Drop Technique, NUREG/CR-4540, U.S. Nuclear Regulatory Commission, Washington, D.C., August 1986 .

15. Wilkowski, G. M., and Maxey, W. A., "Review and Applications of the Electric Potential Method for Neasuring Crack Growth in Specimens, Flawed Pipes, and Pressure Vessels," pp. II-266-II-294 in Fracture Mechanics, Fourteenth Symposium, Vol. II, Testing and Applications, STP 791, J. C. Lewis and J. P. Gudas, Eds., American Society for Testing and Materials, Philadelphia, 1981.

16. Ernst, H. A., "Material Resistance and Instability Beyond J-Controlled Crack Growth," pp. I-191-I-223 in Elastic-P1astic Fracture: Second Symposium, Vo1. I, Inelastic Crack Analysis, STP 803, C. F. Shih and J. P. Gudas, Eds.,American Society for Testing and Materials, Philadelphia, 1983.

17. Nierkle, J. G., and Corten, H., "A J-Integral Analysis for the Compact Specimen, Considering Axial Force as Well as Bending Effects," J. Pressure Vessel Techno1. 96, 286-92 (November 1974).

18. Merkle, J. G., An Examination of Size Effects and Data Scatter Observed in Small Specimen Cleavage Fracture Toughness Testing, NUREG/CR-3672 (ORNL/TM-9088), Oak Ridge National Lab., Oak Ridge, Tenn., April 1984.

19. Paris, P., Tada, H., Zahoor, A., and Ernst, H., "The Theory of Instability of the Tearing Mode for Elastic-Plastic Crack Growth," pp. 5-36 in Elastic-Plastic Fracture, STP 668, J. D. Landes, J. A. Begley, and G. A. Clarke, Eds., American Society for Testing and Materials, Philadelphia, 1979. 
20. Burgers, A., and Kemper, P. D., "Automatic Crack Length Measurement by the Electrical PD Method with Computer Control," pp. 325-42 in Advances in Crack Length Measurement, C. J. Beevers, Ed., Engineering Materials Advisory Services, Ltd., London, 1982.

21. Vecchio, R. S., et a1., "Development of an Automatic Fatigue Crack Propagation Test System, pp. 44-66 in Automated Test Methods for Fracture and Fatigue Crack Growth, STP 877, W. H. Cullen, R. W. Landgraf, L. R. Kaisand, and J. H. Underwood, Eds., American Society for Testing and Materials, Philadelphia, 1985.

22. Bardal, E., et al., "A Pulsed dc Method for the Measurement of Low Fatigue Rates of Crack Growth," pp. 139-58 in Advances in Crack Length Measurement, C. J. Beevers, Ed., Engineering Materials Advisory Services, Itd., London, 1982.

23. Ross, P. J., The Effect of a Superimposed Pressure on Fatigue Crack Propagation in Steel and Aluminum Alloy, Ph.D. Thesis, Universita of Bristol (as referenced in Davis and Plumbridge, see ref. 24).

24. Davis, F. H., and Plumbridge, W. J., "Magnetostrict. -s in Crack Length Measurements," Fatigue Fract. Engrg Mater. Struct. 11(4), 241-50 (1988). 


\section{LIST OF FIGURE GAPTIONS}

Fig. 1. Block diagram showing the components of the ORNL computercontrolled fatigue and fracture testing system.

Fig. 2. ORNL test controller that comprises a multi-output function generator, dc-power supply programmer and CMOS logic on the top plane, and five channels of analog-to-digital conversion and low-pass filters on the lower plane.

Fig. 3. Finite-element mesh used to perform numerical calibration for dc-potential drop calibration for $C(T)$ specimen. Current input and potential voltage lead locations are also shown for one particular combination.

Fig. 4. Comparison of numerical and experimental dc-potential drop calibrations for the $C(T)$ specimen design and lead locations shown in Fig. 3.

Fig. 5. Comparison of $J$ vs crack extension results obtained simultaneously during a test of a $C(T)$ specimen using unloading compliance and dc-potential drop crack measurement techniques.

Fig. 6. Typical waveforms obtained from dc-potential drop experiments with full current and zero current, with and without load, with and without cycling. 
HEWLETT-PACKARD

200/300 SERIES COMPUTER

4MB RAM HP TECH BASIC

ORNL SOFTWARE $1.024 \mathrm{MB}$

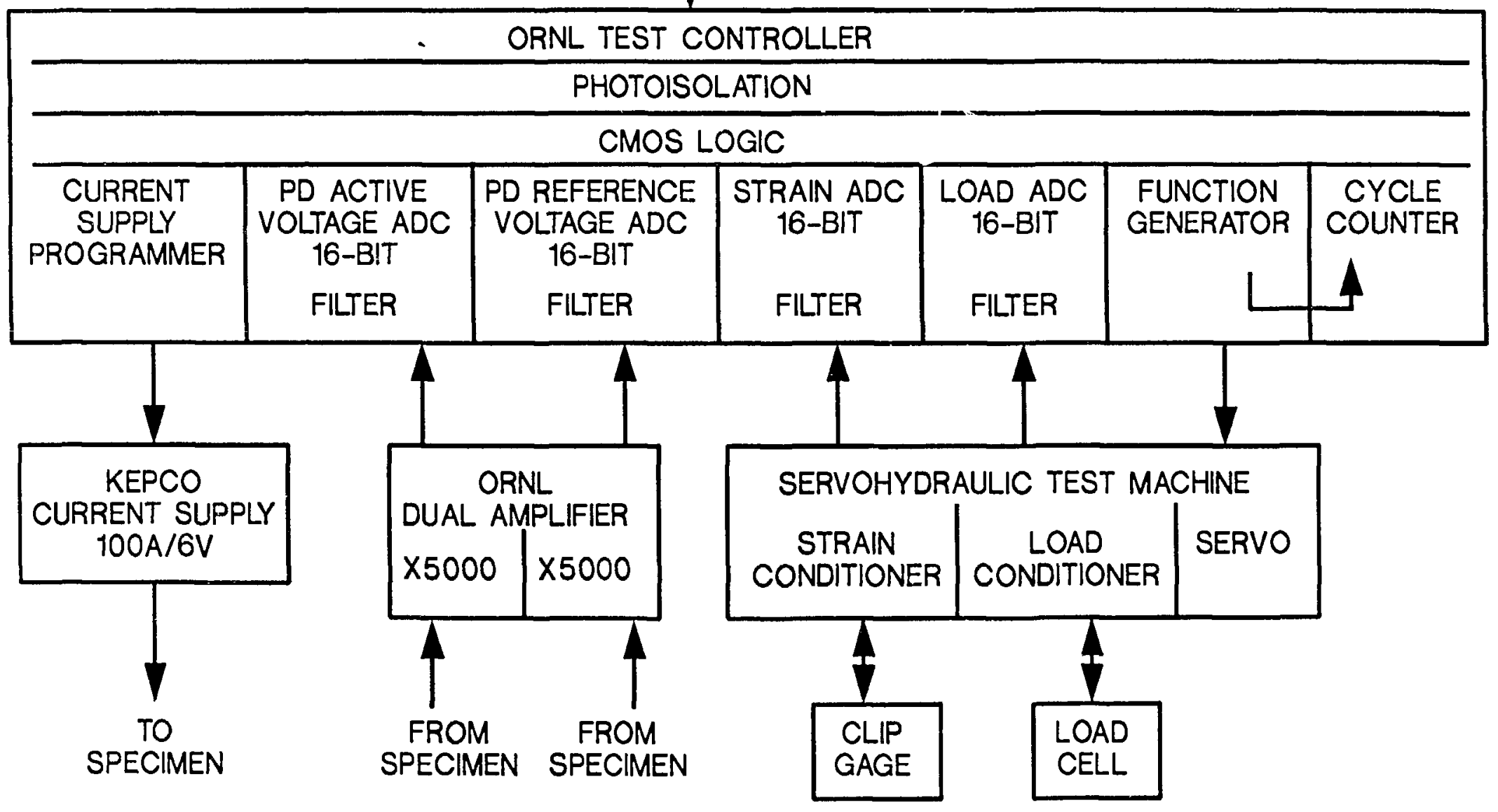




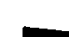

40 What

\section{- $00010 \frac{10}{2}$}

entom

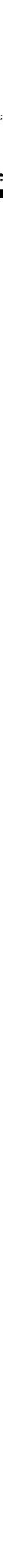




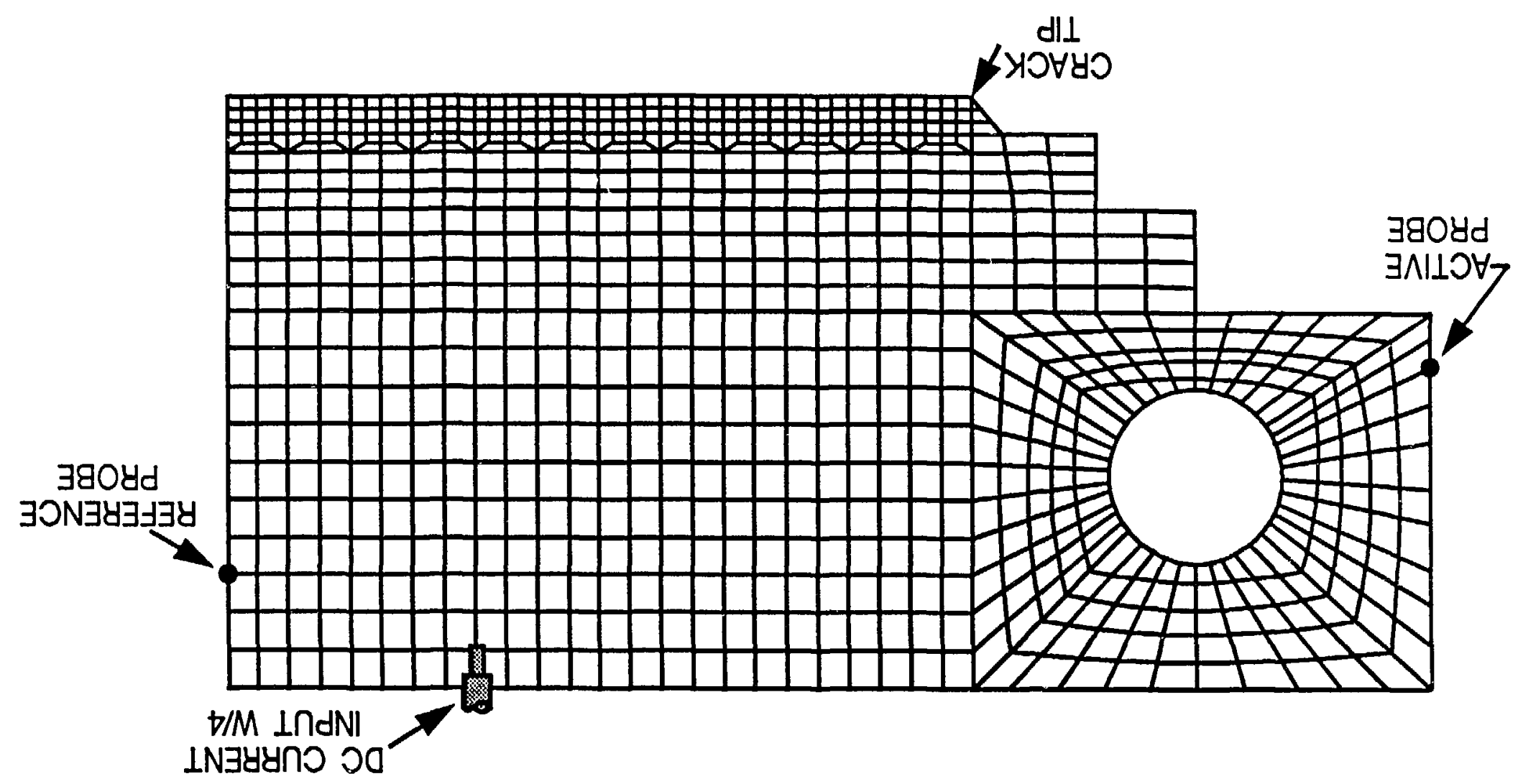




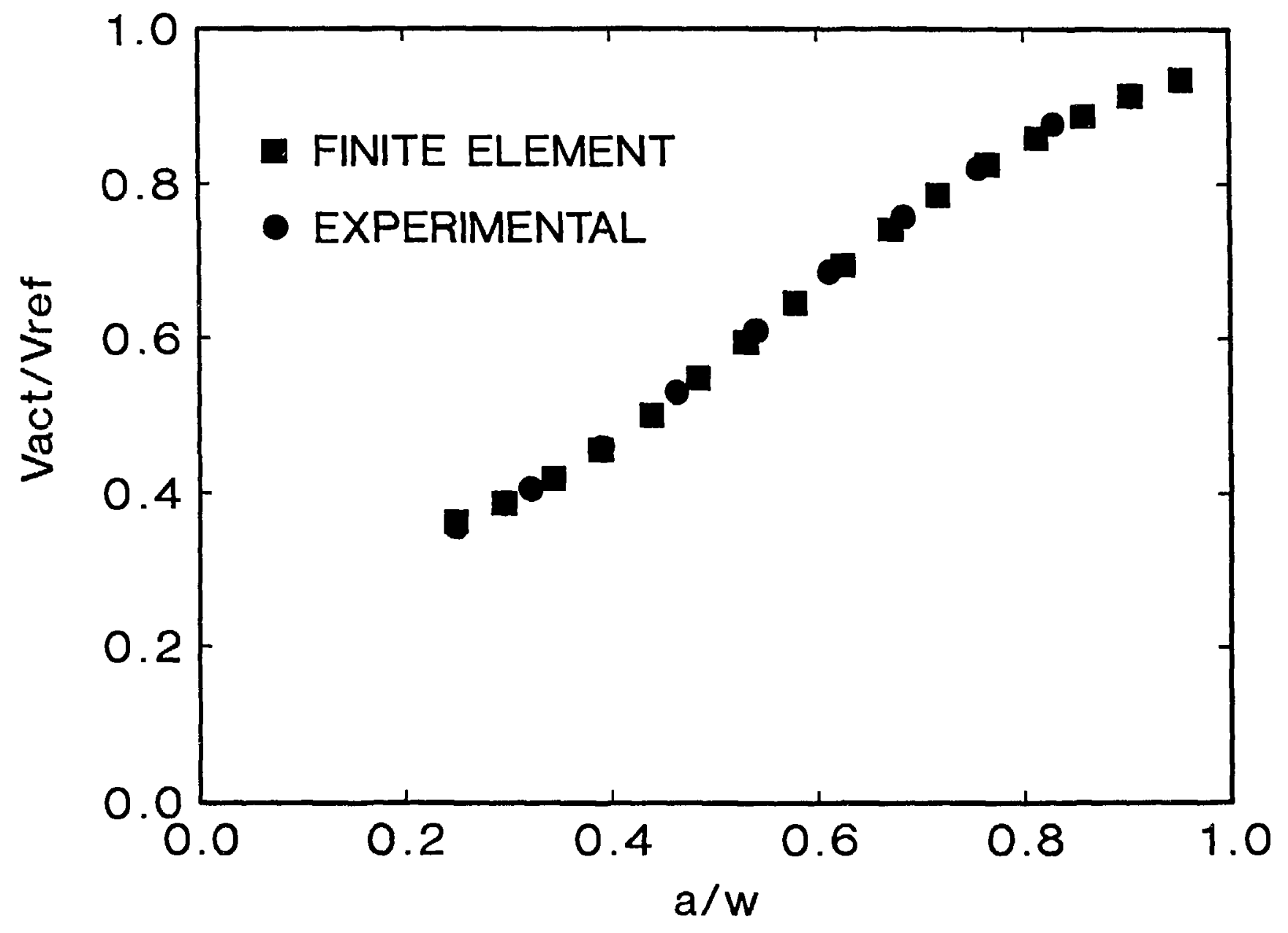




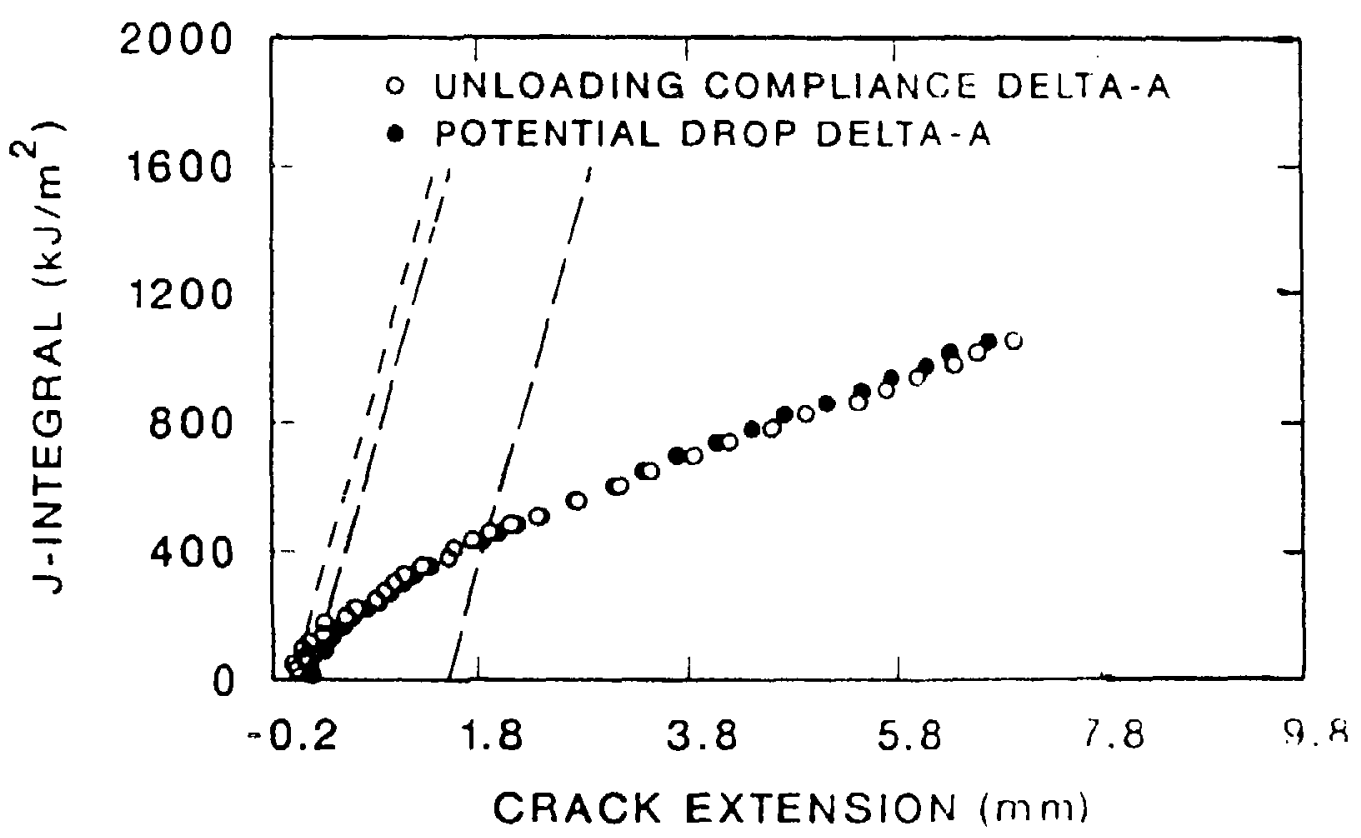




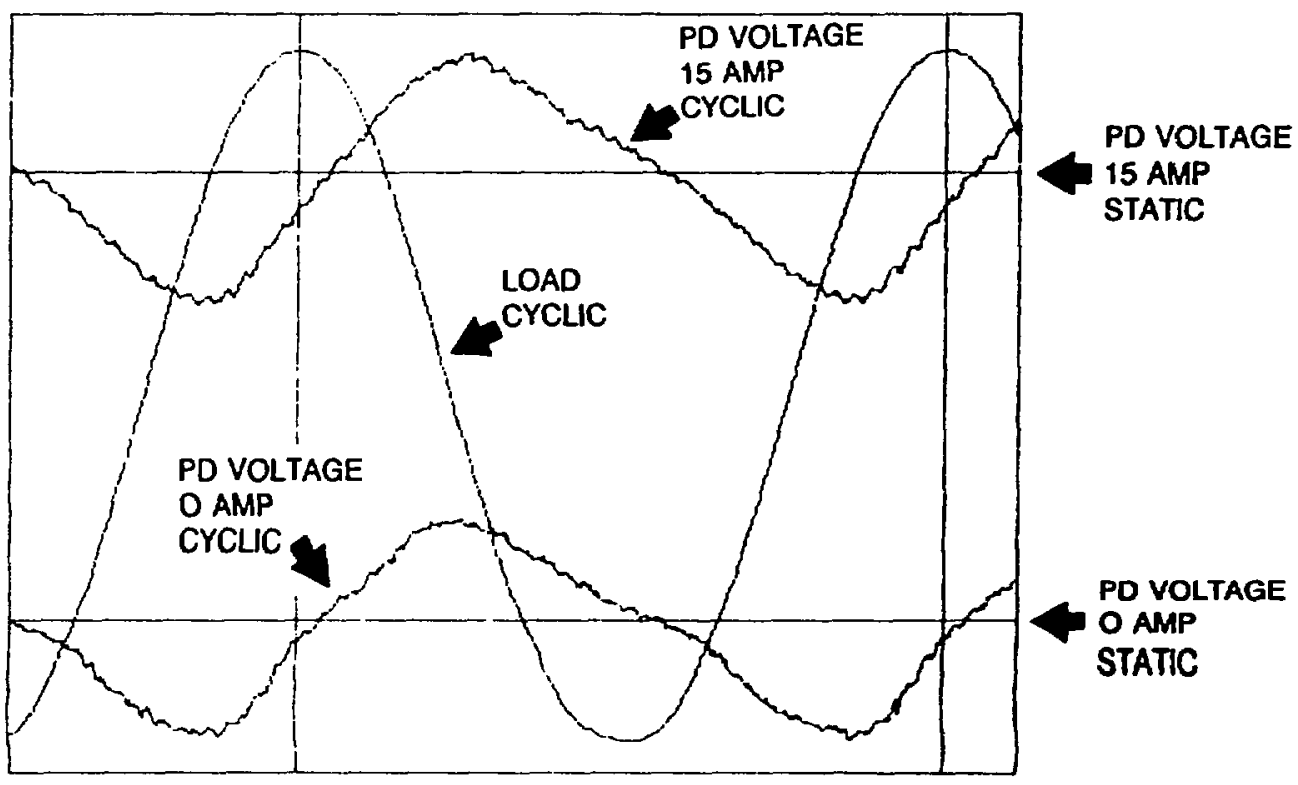

MATERIAL CODE IN BOOGA

MAX LOAD (LB) IO 1500

MIN LOAD (LB) DE 500

LOAD CYCLE FREDUENCY ( $H Z$ ) II 20

CURRENT (A) ID 15

CIJRRENT-OFF VOL TAGE (MV)

STATIC CYCLIC

CURRENT-ON VOL TAGE (MV)

STAIIC CYCLIC

0.15990 .1598
PD ERROR IPERCENT, 0.08 